\title{
Genetics of antigen processing and presentation
}

\author{
Adrian Kelly ${ }^{1} \cdot$ John Trowsdale ${ }^{1}$ \\ Received: 2 August 2018 / Accepted: 24 August 2018 /Published online: 13 September 2018 \\ (C) The Author(s) 2018
}

\begin{abstract}
Immune response to disease requires coordinated expression of an army of molecules. The highly polymorphic MHC class I and class II molecules are key to control of specificity of antigen presentation. Processing of the antigen, to peptides or other moieties, requires other sets of molecules. For classical class I, this includes TAP peptide transporters, proteasome components and Tapasin, genes which are encoded within the MHC. Similarly, HLA-DO and -DM, which influence presentation by HLA class II molecules, are encoded in the MHC region. Analysis of MHC mutants, including point mutations and large deletions, has been central to understanding the roles of these genes. Mouse genetics has also played a major role. Many other genes have been identified including those controlling expression of HLA class I and class II at the transcriptional level. Another genetic approach that has provided insight has been the analysis of microorganisms, including viruses and bacteria that escape immune recognition by blocking these antigen processing and presentation pathways. Here, we provide a brief history of the genetic approaches, both traditional and modern, that have been used in the quest to understand antigen processing and presentation.
\end{abstract}

Keywords MHC $\cdot$ HLA $\cdot$ Antigen processing $\cdot$ Antigen presentation $\cdot$ Genetics

\section{Some history}

The early history of the genetics of antigen processing and presentation followed from the work on histocompatibility in mice, initially by Peter Gorer, who worked at the Lister Institute and Guy's hospital in London. His discovery of the MHC in turn was inspired by three developments. First was the curious pastime of inbreeding mouse strains, a fashionable hobby which spread from China. It reached America in the early 1900s, and after a while, pioneering geneticists realised the advantage of inbred strains for research. Many of the mouse strains were started over 100 years ago. C57BL, one of the original strains, was designated as the mice were black and were number 57 . BALB/c mice were white, on the other hand, and were designated by their originator, Halsey J. Bagg, as Bagg albino, or BALB/c for short. A fascinating early

This article is part of the Topical Collection on Biology and Evolution of Antigen Presentation

John Trowsdale

jt233@cam.ac.uk

1 Department of Pathology, University of Cambridge, Cambridge CB21QP, UK history of these developments is presented in a book on the natural history of the MHC (Klein 1986).

Inbred strains were pivotal in the next development, where researchers used them to study the genetics of tumour rejection. As early as 1903, it was discovered that tumours that grew well when transferred within the same strain were rejected in a different one. Then, in 1922, Little and Johnson showed that transplantation of normal tissue was subject to the same strain specificity as tumours. A third stimulus was the development of blood group research, largely attributed to Landsteiner.

JB Haldane suggested that tumour resistance factors may be akin to blood group antigens, but it was Gorer who performed experiments to test the idea that antigens were shared by both malignant and normal tissues. This led to the formulation of an immunological theory of transplantation, which was later systematised by Peter Medawar. George Snell was studying similar phenomena, and after collaborating with Gorer, he proposed calling the tumour-resistance factors Histocompatibility genes. His approach started to reveal some of the complexity of histocompatibility.

Early work leading to the discovery of the human HLA complex developed in the 1950s and was dependent on the study of antibodies against alloantigens on white blood cells by three laboratories: Jean Dausset in Paris, Rose Payne and 
Walter Bodmer in Stanford, and Jon van Rood in Leiden. It was realised that some patients, and women who had borne several children, tended to make such antibodies, which were independent of $\mathrm{ABO}$ blood groups and erythrocytes. At the time, human organ transplantation was becoming widespread, and it gradually became accepted that human leukocyte antigens were the equivalent of mouse $\mathrm{H}-2$ antigens. The hope was that careful matching, as in ABO, could lead to organ transplants that were not rejected. It was soon realised that the HLA system was more complex than ABO and progress depended on exchange of cells and antisera. The International Histocompatibility Workshops, which have been held every few years since 1964, were critical in interpreting and integrating information obtained with a variety of techniques from different laboratories. Analysis of data from these workshops indicated that a single genetic region was pivotal, namely, in humans, HLA, the Major Histocompatibility Complex. An associated protein chain, $\beta 2$ microglobulin, was identified as a component of HLA antigens and was later mapped outside the complex to chromosome 15 (Goodfellow et al. 1975).

Attempts to develop in vitro assays to study graft rejection led to the mixed lymphocyte reaction (MLR), which also turned out to be controlled by the MHC region. However, the results did not correlate completely with the serologically defined determinants. Work in both human and mouse indicated that these determinants, as well as MLR responsiveness, were both part of the H2 and HLA complexes but were separated genetically. Meanwhile, a different set of experiments showed that levels of antibody response to short synthetic polypeptides were controlled by the MHC. For example, C57 mice responded well to the branched synthetic polypeptide (T, G)-A-L, but CBA animals were poor responders. These effects were traced to the $\mathrm{H}-2$ region leading to the so-called immune response (Ir) genes (Benacerraf and McDevitt 1972).

These many years of work, all indicated that the MHC was a major hub controlling a number of immunological phenomena. Indeed, additional experiments showed that the MHC also controlled susceptibility to viruses. Work in Canberra showed that cytotoxic $\mathrm{T}$ cells simultaneously recognised viral antigens and $\mathrm{MHC}$ molecules, in a phenomenon that came to be known as $\mathrm{MHC}$ restriction (Zinkernagel and Doherty 1974).

The nature of the MHC became even more complex when it was proposed that $\mathrm{T}$ cell suppression was also controlled by the class II region (Green et al. 1983). There followed a decade of controversy over the existence of this phenomenon (Bloom et al. 1992). It was eventually accepted, and the responsible T cells were called regulatory to distinguish them from the confusing history of suppression (Sakaguchi et al. 2007). The genetics behind the controversy concerned the I-J gene which was supposed to map to the I region of the mouse MHC and control the function of suppressor T cells. The I-J antigens were proposed to be soluble molecules secreted by suppressor $\mathrm{T}$ cells. It was a shock to find that discrete I-J genes did not exist once the I region of the mouse had been cloned (Kronenberg et al. 1983).

The genetics of antigen processing and presentation was advanced dramatically in the late 1980s when two further major technical developments helped to get to grips with the complexity. One was the DNA cloning revolution and the second was the determination of the structure of MHC molecules from crystals. Initial cloning of $\mathrm{H}-2$ and HLA antigen genes led quickly to assembly of maps of the MHC in humans and mice. These dramatically simplified the picture to just a handful of class I and class II loci, albeit with a profound level of polymorphism. The early maps of mouse MHC were painstakingly assembled from overlapping cosmids (Steinmetz and Hood 1983). Many different human haplotypes have been analysed by these techniques (Horton et al. 2008; Shiina et al. 2004), as well as using more modern, high-throughput approaches (Norman et al. 2016).

The nature of the polymorphism was mysterious, as class I and class II chains encompassed many amino acid changes seemingly scattered throughout the first two domains of class I and the first domains of both chains of class II. The breakthrough came with the crystal structure of the first MHC antigen, HLA-A2 by Pamela Bjorkman, who was a PhD student at the time in the Wiley/Strominger laboratories (Bjorkman et al. 1987a, Bjorkman et al. 1987b). The realisation that class I and class II molecules possessed a groove which bound peptides immediately swept away other models of antigen recognition, such as those invoking independent receptors for antigen and histocompatibility molecules on $\mathrm{T}$ cells.

The development of molecular immunology through the creation of mutants, DNA sequencing, protein structure and gene discovery then paved the way for uncovering the various components of the antigen processing and presentation pathways, as outlined below (Table 1).

\section{Mutant cell lines}

Panels of HLA homozygous typing cell lines have been important tools in the analysis of human tissue types through HLA classes I and II. These lines were derived by Epstein Barr Virus transformation of lymphoid cells from consanguineous mating, usually first cousin. They have been used for over 40 years by the HLA community and are still in use today (Turner et al. 2018).

Analysis of the involvement of the HLA region in antigen processing and presentation was further enhanced by the generation of deletions and other mutations in lymphoblastoid cell lines (Fig. 1). One series of mutants was made by $\gamma$ ray mutagenesis of the cell line B-LCL721 
Table 1 Some human antigen processing and presenting components. Alternative names and gene designations are given in parentheses

\begin{tabular}{|c|c|c|}
\hline Gene & Comments & Chromosome \\
\hline HLA-A & Classical class I & 6 \\
\hline HLA-B & Classical class I & 6 \\
\hline HLA-C & Classical class I & 6 \\
\hline HLA-E & Non-classical class I & 6 \\
\hline HLA-F & Non-classical class I & 6 \\
\hline HLA-G & Non-classical class I & 6 \\
\hline MICA & Class I-related & 6 \\
\hline MICB & Class I-related & 6 \\
\hline CD1a & Presents lipids & 1 \\
\hline CD1b & Presents lipids & 1 \\
\hline CD1c & Presents lipids & 1 \\
\hline CD1d & Presents lipids & 1 \\
\hline \multicolumn{3}{|l|}{ CD1e } \\
\hline MR1 & Presents metabolites to MAIT cells & 1 \\
\hline HLA-DR & Classical class II & 6 \\
\hline HLA-DQ (HLA-MB, DC) & Classical class II & 6 \\
\hline HLA-DP (HLA-SB) & Classical class II & 6 \\
\hline HLA-DO (HLA-DNA, DZA + HLA-DOB) & Non-classical class II & 6 \\
\hline HLA-DM (RING6 + RING7)) & Non-classical class II & 6 \\
\hline Invariant chain (CD74, Ii) & & 5 \\
\hline$\beta 2$ microglobulin (B2M) & Component of mature class I & 15 \\
\hline LMP2 (PSMB9, RING12) & Inducible proteasome subunit & 6 \\
\hline LMP7 (PSMB8, RING10) & Inducible proteasome subunit & 6 \\
\hline MECL1 (PSMB10) & Inducible proteasome subunit & 16 \\
\hline PA28a (PSME1) & Assembly of immunoproteasome & 14 \\
\hline PA28b (PSME2) & Assembly of immunoproteasome & 14 \\
\hline TAP1 (RING4, PSF1) & Peptide transporter subunit & 6 \\
\hline TAP2 (RING11, PSF2) & Peptide transporter subunit & 6 \\
\hline ERp57 (PDIA3, GRP58) & Oxidoreductase in TAP complex & 15 \\
\hline ERAP1 & Amino peptidase & 5 \\
\hline Tapasin (TAPBP) & Peptide loader & 6 \\
\hline TAPBPR (TAPBPL) & Peptide editor & 12 \\
\hline BIP (HSPA5) & ER chaperone & 9 \\
\hline GILT (IFI30, IP30) & Thiol reductase & 19 \\
\hline PDI (P4HB) & ER chaperone (redox-regulated) & 19 \\
\hline Calreticulin (CALR) & ER chaperone & 19 \\
\hline Calnexin (CANX) & ER chaperone & 5 \\
\hline UGT1 (UGT1A1) & Glucuronosyltransferase & 2 \\
\hline CIITA & Master class II transcription factor & 16 \\
\hline NLRC5 & Master class I transcription factor & 16 \\
\hline
\end{tabular}

by the DeMars group (DeMars et al. 1984; Kavathas et al. 1980). Cells were subjected to 2 cycles of mutagenesis followed by immune-selection with monoclonal antibodies for MHC antigen loss. B-LCL721 contains the following two MHC haplotypes:

$$
\begin{aligned}
& \text { HLA-A } * 01 \text { HLA-B*08 HLA-DRB } 1 * 03 \text { HLA-DPB } 1 * 04 \\
& \text { HLA-A } * 02 \text { HLA-B*51 HLA-DRB1*01 HLA-DPB } 1 * 02
\end{aligned}
$$

More details on the class I HLA types are available on the IPD-IMGT/HLA database. ${ }^{1}$ To our knowledge, not all class II genes have been typed in these cells. Mutant cell lines were isolated by subjecting these cells to irradiation. After 5 days growth, the survivors were selected with complement and a variety of monoclonal antibodies. Analysis of these mutants

\footnotetext{
${ }^{1}$ https://www.ebi.ac.uk/cgi-bin/ipd/imgt/hla/fetch_cell.cgi?10972
} 
showed that they contained large homozygous or hemizygous deletions over the MHC region (Fig. 1). One such line LCL721.174, and its derivative 174xCEM.T2, has been used extensively to investigate TAP transporter function and MHC class I peptide loading. 174xCEM.T2, more commonly referred to as T2, was generated by fusing LCL721.174 with CEMR.3, a T-LCL, and selecting for loss of CEMR.3-derived copies of chromosome 6 (Salter et al. 1985). Both 174XCEM.T2 and LCL721.174 therefore carry the same chromosome 6 MHC deletion.

A similar procedure was used by Andreas Ziegler, using the lymphoma cell line BJAB.B95.8.6 (Spring et al. 1985). The wild-type cells were typed with the resolution available at that time as:

\section{HLA-A $* 1$ HLA-B*35 HLA-C*4 HLA-DR $* 5$ HLA- DQw3 HLA-DP*4$$
\text { HLA-A } * 2 \text { HLA-B*13 HLA-C* HLA-DR* HLA-DQw1 }
$$$$
\text { HLA-DP*2 }
$$

The Pious laboratory used a variation of this approach to isolate mutants in class II (8.1.6 and 9.28.6) by mutagenizing with EMS an HLA-DR3+ cell line, T5-1 (Mellins et al. 1988; Pious et al. 1985). Similarly, in mouse studies designed to investigate the nature of self and non-self-recognition, Klaus Karre generated a murine cell line RMA-S that lacked surface H-2 expression but was rejected in tumour transplant models (Karre et al. 1986). Analysis of this cell line was instrumental in providing early models for peptide loading by MHC class I molecules (Townsend et al. 1989). In addition, Roberto Accolla irradiated Raji cells to produce a mutant line RJ2.2.5 selecting against HLA-DR expression with an antibody D112(Accolla 1983), facilitating identification of CIITA.

These mutant cell lines and their derivatives have been instrumental in a long series of experimental approaches to uncover various components of antigen processing, and they continue to be important tools in investigating their mechanism of action.

\section{TAP transporters}

A key insight into antigen processing was the finding that influenza A-specific cytotoxic T lymphocytes (CTL) recognise discrete epitopes of the nucleoprotein molecule. These
Fig. 1 Composition of the mutant lines derived in the DeMars laboratory (DeMars et al. 1984; Kavathas et al. 1980) and the further derivative T2 (Salter et al. 1985). The shaded boxes show the proposed extents of the deletions. See text for more details of typing. These mutant cells have been used in numerous antigen processing and presentation studies. The Figure adapted from

Demars et al. 1984
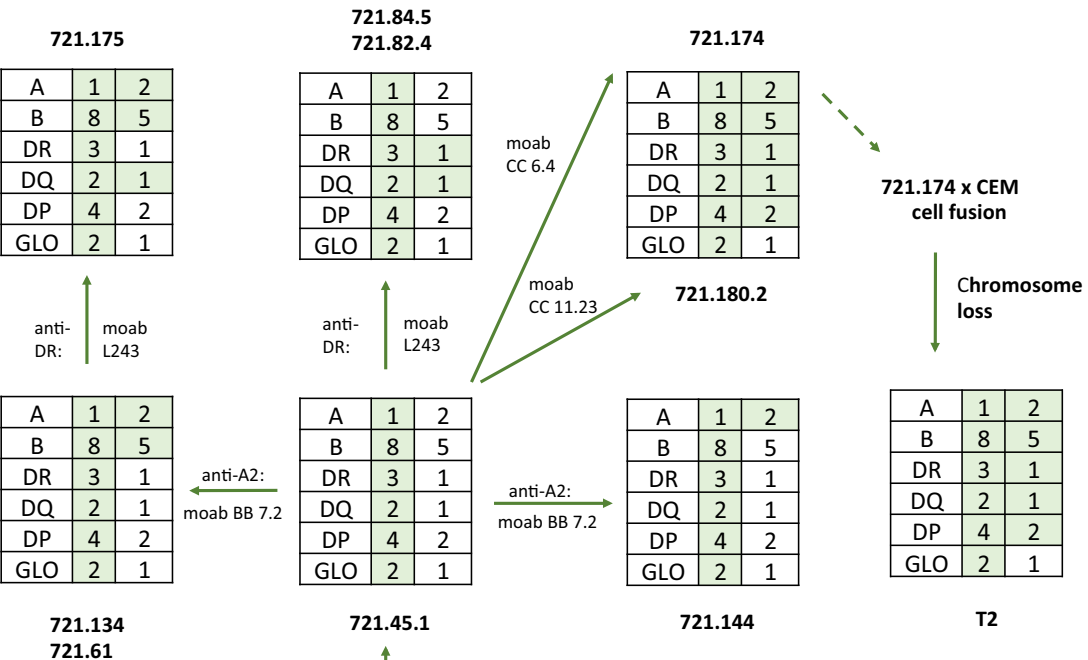

721.144

\begin{tabular}{|c|c|c|}
\hline$A$ & 1 & 2 \\
\hline$B$ & 8 & 5 \\
\hline$D R$ & 3 & 1 \\
\hline DQ & 2 & 1 \\
\hline DP & 4 & 2 \\
\hline GLO & 2 & 1 \\
\hline
\end{tabular}

T2

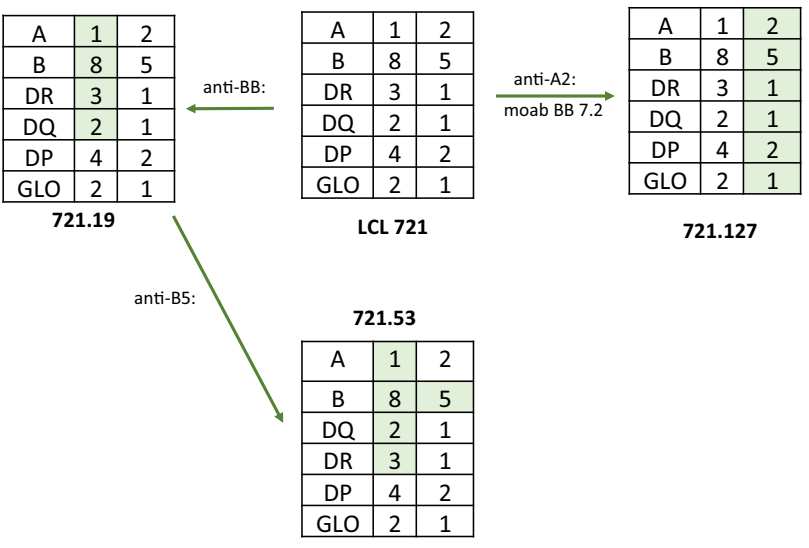


data implied a mechanism for generation of viral protein fragments and their transport to the cell surface for presentation to CTL (Townsend et al. 1985). The peptide-binding groove in HLA molecules was a strong contender for the peptide carrier. There was a problem though in that MHC molecules were integrated into the cell membrane, so how did peptide fragments, which lacked signal sequences, access the endoplasmic reticulum (ER) to be loaded? How were the peptides transported to the cell surface on MHC molecules?

The solution came from MHC mapping and analysis of the mutants referred to above. Several groups simultaneously identified genes encoding transporter molecules mapping to the MHC. These were transporters of the so-called ABC (ATP-binding cassette) type, which were subsequently named TAP, for Transporters Associated with Antigen Processing (Deverson et al. 1990; Monaco et al. 1990; Spies et al. 1990; Trowsdale et al. 1990). These data suggested immediately that the transporters, encoded as a heterodimer of two proteins, TAP1 and TAP2, were responsible for pumping peptides into the ER (Kelly et al. 1992). To confirm this, the TAP1 sequence restored HLA class I expression when transfected into a cell line with a mutant TAP1 gene, LCL721.134 (Spies and DeMars 1991), and the TAP2 sequence restored function and co-precipitation of TAP1 and TAP2 when transfected into cells deficient in TAP2 (Kelly et al. 1992). However, this was not the case when using LCL721.174 cells, which maintained a large deletion over the class II region, covering both components of the heterodimer, TAP1 and TAP2(Spies and DeMars 1991). Studies of rats and chickens were particularly informative as the TAP genes are polymorphic in these species. It turned out that specific allelic versions of TAP supply peptides appropriate for class I molecules whose genes are linked in cis on the haplotype. Inappropriate pairing of TAP alleles with class I alleles they serve with non-binding peptides led to reduced expression of class I, which could be detected at the cell surface (Deverson et al. 1990; Kaufman 2015; Powis et al. 1996).

\section{Natural mutants in TAP}

A number of individuals have been identified with immune-deficiencies due to mutations in TAP (de la Salle et al. 1994; Zimmer et al. 2005). These belong to the category of type I bare lymphocyte (BLS) syndrome, where HLA class I, but not class II, is affected. These patients generally have a severe reduction of class I at the cell surface, but in spite of this, most of these individuals reach adulthood. They are rare and are almost exclusively HLA homozygous due to first cousin parentage. They generally display chronic infections of the respiratory tract (purulent rhinitis, pansinusitis, otitis media) with bacteria (H. influenzae, S. pneumoniae, S. aureus, K. pneumoniae,
E. coli and P. aeruginosa). About half of them exhibit granulomatous skin lesions. This may be due to suboptimal cytokine and cellular responses, leading to tissue damage and favouring subsequent bacterial infection and further recruitment of phagocytic cells. Indeed, antibiotics that impair neutrophils appear to be beneficial.

Patients with defects in TAP do not suffer from severe viral infection. This is unexpected but may relate to the fact that they have a normal humoral (antibody) response and significant numbers of T cells, particularly $\gamma \delta \mathrm{T}$ cells, as well as NK cells and neutrophils. Additionally, presentation of some viral antigens is TAP-independent. Another symptom in these patients is necrotizing granulomatous lesions particularly around the nose, resulting in loss of the septum and associated cartilage. Presentation is variable though. The skin ulcers were found to contain macrophages and NK cells.

In terms of biological effects, the proportion of T cells may be reduced in patients with TAP defects, but there is wide variation in phenotype. They tend to have a higher proportion of $\gamma \delta \mathrm{T}$ cells. Interestingly, numbers of NK cells are normal, but they have no cytotoxic activity against the standard class Inegative targets, unless activated by cytokines.

\section{Proteasome components-LMPs}

At the same time that TAPs were discovered, clues to the proteolytic machinery, responsible for breaking the antigenic proteins into peptides, were also provided, by studying mutants over the MHC region. The biochemical prelude to this discovery came in the early 1980s when Monaco and McDevitt described a series of up to16 low-molecular weight proteins, LMPs, that mapped to the MHC. Initially, the functions of these proteins were not obvious, but they formed a complex by co-precipitation and varied between different mouse haplotypes, in other words were polymorphic (Monaco and McDevitt 1984). It was subsequently established that genes for two interferon-inducible, catalytic proteasome subunits, LMP2 (PSMB9; $\beta 1 \mathrm{i}$ ) and LMP7 (PSMB8: $\beta 5 \mathrm{i}$ ), were closely linked to the TAP1 and TAP2 genes in both human and mouse MHC (Glynne et al. 1991; Kelly et al. 1991a). As with the TAPs, finding proteasome components encoded in the MHC immediately suggested that the proteasome was responsible for producing the antigenic peptides. Proteasomes are ubiquitous cellular components responsible for continual turnover of proteins in general. However, the MHC-encoded proteasome genes were interferon inducible and, when expressed, replaced constitutive components in a subset of the main structures. Another interferoninducible subunit PSMB10 ( $\beta 2 \mathrm{i})$ is encoded outside the MHC on chromosome $16 \mathrm{q} 22.1$. 


\section{ERp57 and ERAP1}

A number of chaperones are associated with class I as it matures and picks up peptide in the peptide-loading complex. These chaperones serve multiple proteins in the ER and are not dedicated to class I. However, ERp57 is a component of the peptide-loading complex. The protein aids folding of nascent glycoproteins by facilitating disulphide bond isomerisation.

ERAP1 is an amino peptidase. It plays a role in determining the length and sequence of peptides bound and presented by class I allotypes. HLA-B27 is strongly associated with ankylosing spondylitis (Chen et al. 2014), and genetic studies indicated that certain ERAP1 allotypes are more associated with ankylosing spondylitis than others, due to their contribution to peptide trimming (Reeves et al. 2014a, Reeves et al. 2014b). There has been some controversy over this effect as it was difficult to analyse genetically. It was proposed to involve specific combinations of different ERAP1 allotypes, making association studies difficult (Reeves et al. 2015; Robinson and Brown 2015).

\section{TAPASIN}

The gene for Tapasin, another component of the antigen processing machinery, is located just outside the MHC region (Ortmann et al. 1997). The product of this gene, which is an additional member of the immunoglobulin gene family, links the peptide transporter to the nascent class I molecule in a complex, the peptide-loading complex (Blees et al. 2017). Optimisation of the MHC class I peptide cargo is proposed to be dependent on Tapasin (Williams et al. 2002). However, class I molecules vary in their dependence on the protein, an effect that has been mapped to specific positions on the HLA molecule (Park et al. 2003) as well as to its conformational flexibility (Garstka et al. 2011). For example, the HLA-B*44 allele, which differs exclusively at position 156, B*44:02 (156Asp), is Tapasin-dependent, whereas other alleles are not (Badrinath et al. 2012). The reason for this is not known but could relate to the fact that some virus products compromise antigen presentation by interacting with the Tapasin protein.

\section{TAPBPR}

There is evidence that the jawed vertebrate genome has undergone duplication at least twice in its evolutionary history, according to the $2 \mathrm{R}$ hypothesis. Accordingly, it was demonstrated that there are traces of at least four clusters of genes related to those in the MHC proper on chromosome 6 (Kasahara 1999). One paralogous region, identified by Louis Du
Pasquier, was at chromosome position 12p13.3. A gene in this region shared sequence homology with Tapasin, dubbed TAPBPR (Teng et al. 2002). The product of this gene was subsequently shown to be a novel component of the MHC class I presentation pathway, which acts as a peptide exchange catalyst (Hermann et al. 2015; Neerincx and Boyle 2017). TAPBPR interacts with class I in a similar manner to Tapasin but is not complexed to TAP (Jiang et al. 2017). TAPBPR links UDP-glucose:glycoprotein glucosyltransferase 1 onto MHC class I (Neerincx et al. 2017). Tapasin is monomorphic, but TAPBPR is relatively polymorphic and there are a number of common alleles and splice variants in humans (Porter et al. 2014). The relationship between the products of these alleles and MHC Class I loci and alleles is not known. As with Tapasin, it appears that some alleles of class I are dependent, and others independent, of the molecule.

\section{HLA-DM and DO}

The existence of an MHC-encoded factor that was essential for MHC class II antigen presentation was first suggested through the characterisation of mutagenised $\mathrm{B}$ lymphoblastoid cells selected for loss of HLA-DR3 reactivity with a DR3specific antibody, 16:23(Mellins et al. 1990). These cells had normal levels of cell surface DR but were unable to present native antigen to $\mathrm{T}$ cells. They possessed class II molecules that were predominantly filled with the CLIP peptide and fell apart in the presence of SDS. The defect was eventually mapped to HLA-DM (Morris et al. 1994), a class II-related molecule previously identified in both mouse and human in screens for expressed genes encoded on cosmids spanning the MHC region (Kelly et al. 1991b; Cho et al. 1991). HLA-DM acts as a peptide editing chaperone stabilising class II whilst exchanging CLIP for antigenic peptide. DM activity is regulated by a second non-classical class II molecule, now called HLA-DO. HLA-DO alpha and beta chains were first identified due to their high homology with human and murine classical class II molecules (Larhammar et al. 1985; Tonnelle et al. 1985; Trowsdale and Kelly 1985). It proved much harder to decipher the role of DO even though the molecule was identified some 6 years before DM. DOA and DOB were not located together in the MHC, and the chains showed different mRNA expression patterns initially suggesting that they would not associate as a pair. DO resides in late endosomal compartments but requires association with DM in the endoplasmic reticulum for correct assembly (Liljedahl et al. 1996). The in vivo role of DO is still debatable, but mechanistically, it functions as a negative regulator of DM activity (van Ham et al. 1997; Denzin et al. 1997). Unlike the transient interactions seen between DM and DR, the DM/DO interaction is very stable, suggesting that $\mathrm{DO}$ acts as a competitive inhibitor 
of DM, a view consistent with the DM/DO crystal structure (Guce et al. 2013).

\section{Haplotypes and linkage disequilibrium}

It has been known for some time that the MHC comprises a large region in linkage disequilibrium (LD), or polymorphic frozen blocks (Dawkins et al. 1999). In some populations, for example, combinations of alleles, such as HLA-A1-B8-DR3, are more commonly found together than would be expected based on frequencies of individual alleles in the population. Several mechanisms may be invoked to explain this. First, there may have been insufficient time for recombination after relatively recent expansion of families, in some cases in isolated populations. Another possibility is that recombination 'cold spots' in the MHC sequence restrain the level of exchange of alleles between haplotypes. This may be facilitated by a reduced level of pairing at meiosis in a region such as the $\mathrm{MHC}$, where the variation between haplotypes compromises homologous interaction. Indeed, overall recombination is low in the MHC.

An attractive explanation for the high LD is clustering of alleles that encode proteins that work well together and maintenance of functionally coordinated sets of alleles. As discussed above, the discovery of both TAP transporters and LMP proteasome components mapping to the MHC was largely serendipitous and was inspired to some extent by the notion that the MHC was a cluster of genes with inter-related functions. Furthermore, it was proposed that linkage of polymorphic transporters with polymorphic MHC class I genes permitted functional coordination, such that appropriate binding peptides, for the class I molecules linked in cis, were pumped by the relevant TAP. This turned out to be the case for rats and chickens, where genes for class I and TAP are in close proximity (Powis et al. 1992; Tregaskes et al. 2016). In the human MHC TAP transporters, genes are separated from the class I genes they serve by the class III region, so this functional integration may not be fully operational in our species. Another consideration is that each individual has two haplotypes, the various components of which must cooperate to some extent.

Recent data add weight to the notion of a high degree of allelic integration on individual haplotypes. It is becoming appreciated that, in addition to protein-coding loci, other polymorphic genomic features are embedded in the MHC complex. One clue to this came from the finding that a single nucleotide polymorphism (SNP) $35 \mathrm{~kb}$ upstream of HLA-C associated with levels of mRNA transcript and cell-surface expression (Kulkarni et al. 2011). Binding of microRNA hsa-miR-148 to a variable $3^{\prime}$ untranslated region in HLA-C genes regulated their expression. The conclusion was that expression levels may be regulated both by cis- and trans-acting factors. A further indication of the integration along haplotypes came from data relating to the way that class I molecules 'educate' by interacting with receptors on NK cells. Hydrophobic leader sequences from class I molecules supply peptides that bind HLA-E, which instructs CD94/NKG2A receptors on NK cells. Leader sequences of HLA-B molecules are dimorphic: Those with -21 methionine $(-21 \mathrm{M})$ provide peptides that bind HLA-E, whereas -21 threonine do not. Those haplotypes with $-21 \mathrm{M}$ rarely encode the ligands for other NK receptors, namely Bw4+ HLA-B and C2+ HLA-C. From these data, it was proposed that there are two schools of HLA haplotypes; one focused on supplying CD94/NKG2A ligands, and the other, KIR ligands. Individuals with $-21 \mathrm{M}$ had NKG2A+ cells that were more effective than those with only $-21 \mathrm{~T}$ (Horowitz et al. 2016). Similarly, HLA-A leader sequences determine expression levels of HLA-E, again influencing interaction with CD94/NKG2A on NK cells and in turn HIV replication (Ramsuran et al. 2018).

\section{Regulation of transcription and translation}

Analysis of mutants has also been productive for identifying regulators of antigen processing and presenting genes. For many years, it was difficult to track down a master regulator of class I. On the other hand, mutants affecting class II were isolated from bare lymphocyte patients (Reith and Mach 2001). The class II master regulator CIITA is a nucleotidebinding domain and leucine-rich repeat receptor (NLR) protein. This large gene was initially found by expression cloning in a class II-deficient cell line (Steimle et al. 1993). Mutants invoking loss of function of CIITA generally result in severe immunodeficiency, a form of bare lymphocyte syndrome. Individuals with BLS have impaired antibody and $\mathrm{T}$ cell responses due to the lack of MHC class II expression. Class II transcription requires, in addition to CIITA, at least three additional factors: RFX5, RFX-AP and RFX-ANK. The genes encoding these factors were identified by comparing panels of rare BLS patients and mutant cell lines selected for loss of class II expression. This identified four complementation groups. Transient heterokaryon fusions between these cell lines restored class II expression if the partners harboured defects in different components, thereby defining the four groups. A combination of genetic complementation and protein characterisation eventually identified the genetic lesions, as reviewed in Reith and Mach (2001).

It was only in the last decade that a master transcription regulator for class I was discovered (Kobayashi and Elsen, 2012; Meissner et al. 2010; Neerincx et al. 2013). Like the class II transcription activator, CIITA, NLRC5 is an NLR protein and the two molecules share some homology. In cell lines defective in class I expression, such as mouse melanoma B16F10, over-expressed NLRC5 could restore class I 
expression. In human cells, over-expression of NLRC5 resulted in induction of non-classical class I genes HLA-E, -F and $\mathrm{G}$, which normally exhibit a restricted tissue expression. CIITA-dependent activation of HLA class II requires the enhanceosome complex, which binds to a motif, SXY, in the promoter of the gene. NLRCF probably interacts with a similar module upstream of class I genes.

Confirmation of the role of NLRC5 in regulation of MHC class I was provided by studying Nlrc5-deficient knock-out mice (Staehli et al. 2012). The data showed that MHC class I was downregulated, exhibiting the greatest effect in cells in the immune system. However, treatment of these mice with inflammatory stimuli, such as interferon or LPS, resulted in significant class I expression, indicating that Nlrc5-independent mechanisms must exist to regulate MHC class I.

Recent work suggests that there is still more to learn about variation in HLA expression. For example, the Anderson laboratory identified an elaborate system regulating forms of HLA-C, which is specific to natural killer cells, and could relate to NK cell licencing or education ( $\mathrm{Li}$ et al. 2018). Other work suggests that, in addition to allelic differences, levels of class I should be taken into account in relation to autoimmunity, infection and transplantation (Apps et al. 2013; Kaur et al. 2017; Li et al. 2018; Petersdorf et al. 2014).

\section{Screening for novel components}

New screening techniques have the potential to identify novel factors involved in MHC biology. For example, forward genetic screens involving retroviral insertional mutagenesis or random CRISPR/Cas9 targeting of a haploid human cell line KBM7 implicate TXNDC11 as a novel factor required for MHC class I endoplasmic reticulum-associated protein degradation (ERAD) (Timms et al. 2016). In addition, a genomewide RNAi screen was used to identify pathways regulating MHC class II antigen presentation (Paul et al. 2011).

\section{Conclusion}

Immunogenetics has played a predominant role in uncovering many of the fundamentals of antigen processing and presentation. In this review, we have sketched out some of the history and background to the genetics, focussing mainly on the human system. Other contributions to this volume of Immunogenetics may be consulted for more in-depth coverage of individual components of antigen processing and presentation.

Funding information JT is supported by the European Research Council under the European Union's Horizon 2020 research and innovation programme (Grant agreement No. 695551).
Open Access This article is distributed under the terms of the Creative Commons Attribution 4.0 International License (http:// creativecommons.org/licenses/by/4.0/), which permits unrestricted use, distribution, and reproduction in any medium, provided you give appropriate credit to the original author(s) and the source, provide a link to the Creative Commons license, and indicate if changes were made.

\section{References}

Accolla RS (1983) Human B cell variants immunoselected against a single Ia antigen subset have lost expression of several Ia antigen subsets. J Exp Med 157:1053-1058

Apps R, Qi Y, Carlson JM, Chen H, Gao X, Thomas R, Yuki Y, Del Prete GQ, Goulder P, Brumme ZL, Brumme CJ, John M, Mallal S, Nelson G, Bosch R, Heckerman D, Stein JL, Soderberg KA, Moody MA, Denny TN, Zeng X, Fang J, Moffett A, Lifson JD, Goedert JJ, Buchbinder S, Kirk GD, Fellay J, McLaren P, Deeks SG, Pereyra F, Walker B, Michael NL, Weintrob A, Wolinsky S, Liao W, Carrington M (2013) Influence of HLA-C expression level on HIV control. Science 340:87-91

Badrinath S, Saunders P, Huyton T, Aufderbeck S, Hiller O, Blasczyk R, Bade-Doeding C (2012) Position 156 influences the peptide repertoire and tapasin dependency of human leukocyte antigen $\mathrm{B}^{*} 44$ allotypes. Haematologica 97:98-106

Benacerraf B, McDevitt HO (1972) Histocompatibility-linked immune response genes. Science 175:273-279

Bjorkman PJ, Saper MA, Samraoui B, Bennett WS, Strominger JL, Wiley DC (1987a) The foreign antigen binding site and T cell recognition regions of class I histocompatibility antigens. Nature 329:512-518

Bjorkman PJ, Saper MA, Samraoui B, Bennett WS, Strominger JL, Wiley DC (1987b) Structure of the human class I histocompatibility antigen, HLA-A2. Nature 329:506-512

Blees A, Januliene D, Hofmann T, Koller N, Schmidt C, Trowitzsch S, Moeller A, Tampe R (2017) Structure of the human MHC-I peptideloading complex. Nature 551:525-528

Bloom BR, Salgame P, Diamond B (1992) Revisiting and revising suppressor T cells. Immunol Today 13:131-136

Chen L, Fischer R, Peng Y, Reeves E, McHugh K, Ternette N, Hanke T, Dong T, Elliott T, Shastri N, Kollnberger S, James E, Kessler B, Bowness P (2014) Critical role of endoplasmic reticulum aminopeptidase 1 in determining the length and sequence of peptides bound and presented by HLA-B27. Arthritis Rheumatol 66:284-294

Cho SG, Attaya M, Monaco JJ (1991) New class II-like genes in the murine MHC. Nature 353:573-576

Dawkins R, Leelayuwat C, Gaudieri S, Tay G, Hui J, Cattley S, Martinez P, Kulski J (1999) Genomics of the major histocompatibility complex: haplotypes, duplication, retroviruses and disease. Immunol Rev 167:275-304

de la Salle H, Hanau D, Fricker D, Urlacher A, Kelly A, Salamero J, Powis SH, Donato L, Bausinger H, Laforet M et al (1994) Homozygous human TAP peptide transporter mutation in HLA class I deficiency. Science 265:237-241

DeMars R, Chang CC, Shaw S, Reitnauer PJ, Sondel PM (1984) Homozygous deletions that simultaneously eliminate expressions of class I and class II antigens of EBV-transformed Blymphoblastoid cells. I. Reduced proliferative responses of autologous and allogeneic $\mathrm{T}$ cells to mutant cells that have decreased expression of class II antigens. Hum Immunol 11:77-97

Denzin LK, Sant'Angelo DB, Hammond C, Surman MJ, Cresswell P (1997) Negative regulation by HLA-DO of MHC class IIrestricted antigen processing. Science 278:106-109 
Deverson EV, Gow IR, Coadwell WJ, Monaco JJ, Butcher GW, Howard JC (1990) MHC class II region encoding proteins related to the multidrug resistance family of transmembrane transporters. Nature 348:738-741

Garstka MA, Fritzsche S, Lenart I, Hein Z, Jankevicius G, Boyle LH, Elliott T, Trowsdale J, Antoniou AN, Zacharias M, Springer S (2011) Tapasin dependence of major histocompatibility complex class I molecules correlates with their conformational flexibility. FASEB J 25:3989-3998

Glynne R, Powis SH, Beck S, Kelly A, Kerr LA, Trowsdale J (1991) A proteasome-related gene between the two ABC transporter loci in the class II region of the human MHC. Nature 353:357-360

Goodfellow PN, Jones EA, Van Heyningen V, Solomon E, Bobrow M, Miggiano V, Bodmer WF (1975) The beta2-microglobulin gene is on chromosome 15 and not in the HL-A region. Nature 254:267269

Green DR, Flood PM, Gershon RK (1983) Immunoregulatory T-cell pathways. Annu Rev Immunol 1:439-463

Guce AI, Mortimer SE, Yoon T, Painter CA, Jiang W, Mellins ED, Stern LJ (2013) HLA-DO acts as a substrate mimic to inhibit HLA-DM by a competitive mechanism. Nat Struct Mol Biol 20:90-98

Hermann C, van Hateren A, Trautwein N, Neerincx A, Duriez PJ, Stevanovic S, Trowsdale J, Deane JE, Elliott T, Boyle LH (2015) TAPBPR alters MHC class I peptide presentation by functioning as a peptide exchange catalyst. Elife 4

Horowitz A, Djaoud Z, Nemat-Gorgani N, Blokhuis J, Hilton HG, Beziat V, Malmberg KJ, Norman PJ, Guethlein LA, Parham P (2016) Class I HLA haplotypes form two schools that educate NK cells in different ways. Sci Immunol 1:eaag1672

Horton R, Gibson R, Coggill P, Miretti M, Allcock RJ, Almeida J, Forbes S, Gilbert JG, Halls K, Harrow JL, Hart E, Howe K, Jackson DK, Palmer S, Roberts AN, Sims S, Stewart CA, Traherne JA, Trevanion S, Wilming L, Rogers J, de Jong PJ, Elliott JF, Sawcer S, Todd JA, Trowsdale J, Beck S (2008) Variation analysis and gene annotation of eight MHC haplotypes: the MHC haplotype project. Immunogenetics 60:1-18

Jiang J, Natarajan K, Boyd LF, Morozov GI, Mage MG, Margulies DH (2017) Crystal structure of a TAPBPR-MHC I complex reveals the mechanism of peptide editing in antigen presentation. Science 358: 1064-1068

Karre K, Ljunggren HG, Piontek G, Kiessling R (1986) Selective rejection of H-2-deficient lymphoma variants suggests alternative immune defence strategy. Nature 319:675-678

Kasahara M (1999) The chromosomal duplication model of the major histocompatibility complex. Immunol Rev 167:17-32

Kaufman J (2015) Co-evolution with chicken class I genes. Immunol Rev 267:56-71

Kaur G, Gras S, Mobbs JI, Vivian JP, Cortes A, Barber T, Kuttikkatte SB, Jensen LT, Attfield KE, Dendrou CA, Carrington M, McVean G, Purcell AW, Rossjohn J, Fugger L (2017) Structural and regulatory diversity shape HLA-C protein expression levels. Nat Commun 8: 15924

Kavathas P, Bach FH, DeMars R (1980) Gamma ray-induced loss of expression of HLA and glyoxalase I alleles in lymphoblastoid cells. Proc Natl Acad Sci U S A 77:4251-4255

Kelly A, Powis SH, Glynne R, Radley E, Beck S, Trowsdale J (1991a) Second proteasome-related gene in the human MHC class II region. Nature 353:667-668

Kelly A, Powis SH, Kerr LA, Mockridge I, Elliott T, Bastin J, UchanskaZiegler B, Ziegler A, Trowsdale J, Townsend A (1992) Assembly and function of the two $\mathrm{ABC}$ transporter proteins encoded in the human major histocompatibility complex. Nature 355:641-644

Kelly AP, Monaco JJ, Cho SG, Trowsdale J (1991b) A new human HLA class II-related locus, DM. Nature 353:571-573

Klein J (1986) Natural history of the major histocompatibility complex. Wiley, New York
Kobayashi KS, van den Elsen PJ (2012) NLRC5: a key regulator of MHC class I-dependent immune responses. Nat Rev Immunol 12:813820

Kronenberg M, Steinmetz M, Kobori J, Kraig E, Kapp JA, Pierce CW, Sorensen CM, Suzuki G, Tada T, Hood L (1983) RNA transcripts for I-J polypeptides are apparently not encoded between the I-A and I-E subregions of the murine major histocompatibility complex. Proc Natl Acad Sci U S A 80:5704-5708

Kulkarni S, Savan R, Qi Y, Gao X, Yuki Y, Bass SE, Martin MP, Hunt P, Deeks SG, Telenti A, Pereyra F, Goldstein D, Wolinsky S, Walker B, Young HA, Carrington M (2011) Differential microRNA regulation of HLA-C expression and its association with HIV control. Nature 472:495-498

Larhammar D, Hammerling U, Rask L, Peterson PA (1985) Sequence of gene and cDNA encoding murine major histocompatibility complex class II gene A beta 2. J Biol Chem 260:14111-14119

Li H, Ivarsson MA, Walker-Sperling VE, Subleski J, Johnson JK, Wright PW, Carrington M, Bjorkstrom NK, McVicar DW, Anderson SK (2018) Identification of an elaborate NK-specific system regulating HLA-C expression. PLoS Genet 14:e1007163

Liljedahl M, Kuwana T, Fung-Leung WP, Jackson MR, Peterson PA, Karlsson L (1996) HLA-DO is a lysosomal resident which requires association with HLA-DM for efficient intracellular transport. EMBO J 15:4817-4824

Meissner TB, Li A, Biswas A, Lee KH, Liu YJ, Bayir E, Iliopoulos D, van den Elsen PJ, Kobayashi KS (2010) NLR family member NLRC5 is a transcriptional regulator of MHC class I genes. Proc Natl Acad Sci U S A 107:13794-13799

Mellins E, Arp B, Ochs B, Erlich H, Pious D (1988) A single amino acid substitution in the human histocompatibility leukocyte antigen DR3 beta chain selectively alters antigen presentation. J Exp Med 168: $1531-1537$

Mellins E, Smith L, Arp B, Cotner T, Celis E, Pious D (1990) Defective processing and presentation of exogenous antigens in mutants with normal HLA class II genes. Nature 343:71-74

Monaco JJ, Cho S, Attaya M (1990) Transport protein genes in the murine MHC: possible implications for antigen processing. Science 250:1723-1726

Monaco JJ, McDevitt HO (1984) H-2-linked low-molecular weight polypeptide antigens assemble into an unusual macromolecular complex. Nature 309:797-799

Morris P, Shaman J, Attaya M, Amaya M, Goodman S, Bergman C, Monaco JJ, Mellins E (1994) An essential role for HLA-DM in antigen presentation by class II major histocompatibility molecules. Nature 368:551-554

Neerincx A, Boyle LH (2017) Properties of the tapasin homologue TAPBPR. Curr Opin Immunol 46:97-102

Neerincx A, Castro W, Guarda G, Kufer TA (2013) NLRC5, at the heart of antigen presentation. Front Immunol 4:397

Neerincx A, Hermann C, Antrobus R, van Hateren A, Cao H, Trautwein N, Stevanovic S, Elliott T, Deane JE, Boyle LH (2017) TAPBPR bridges UDP-glucose:glycoprotein glucosyltransferase 1 onto MHC class I to provide quality control in the antigen presentation pathway. Elife 6

Norman PJ, Hollenbach JA, Nemat-Gorgani N, Marin WM, Norberg SJ, Ashouri E, Jayaraman J, Wroblewski EE, Trowsdale J, Rajalingam R, Oksenberg JR, Chiaroni J, Guethlein LA, Traherne JA, Ronaghi M, Parham P (2016) Defining KIR and HLA class I genotypes at highest resolution via high-throughput sequencing. Am J Hum Genet 99:375-391

Ortmann B, Copeman J, Lehner PJ, Sadasivan B, Herberg JA, Grandea AG, Riddell SR, Tampe R, Spies T, Trowsdale J, Cresswell P (1997) A critical role for tapasin in the assembly and function of multimeric MHC class I-TAP complexes. Science 277:1306-1309 
Park B, Lee S, Kim E, Ahn K (2003) A single polymorphic residue within the peptide-binding cleft of MHC class I molecules determines spectrum of tapasin dependence. J Immunol 170:961-968

Paul P, van den Hoorn T, Jongsma ML, Bakker MJ, Hengeveld R, Janssen L, Cresswell P, Egan DA, van Ham M, Ten Brinke A, Ovaa H, Beijersbergen RL, Kuijl C, Neefjes J (2011) A genomewide multidimensional RNAi screen reveals pathways controlling MHC class II antigen presentation. Cell 145:268-283

Petersdorf EW, Gooley TA, Malkki M, Bacigalupo AP, Cesbron A, Du Toit E, Ehninger G, Egeland T, Fischer GF, Gervais T, Haagenson MD, Horowitz MM, Hsu K, Jindra P, Madrigal A, Oudshoorn M, Ringden O, Schroeder ML, Spellman SR, Tiercy JM, Velardi A, Witt CS, O'Huigin C, Apps R, Carrington M, International Histocompatibility Working Group in Hematopoietic Cell T (2014) HLA-C expression levels define permissible mismatches in hematopoietic cell transplantation. Blood 124:3996-4003

Pious D, Dixon L, Levine F, Cotner T, Johnson R (1985) HLA class II regulation and structure. Analysis with HLA-DR3 and HLA-DP point mutants. J Exp Med 162:1193-1207

Porter KM, Hermann C, Traherne JA, Boyle LH (2014) TAPBPR isoforms exhibit altered association with MHC class I. Immunology 142:289-299

Powis SJ, Deverson EV, Coadwell WJ, Ciruela A, Huskisson NS, Smith H, Butcher GW, Howard JC (1992) Effect of polymorphism of an MHC-linked transporter on the peptides assembled in a class I molecule. Nature 357:211-215

Powis SJ, Young LL, Joly E, Barker PJ, Richardson L, Brandt RP, Melief CJ, Howard JC, Butcher GW (1996) The rat cim effect: TAP alleledependent changes in a class I MHC anchor motif and evidence against C-terminal trimming of peptides in the ER. Immunity 4: $159-165$

Ramsuran V, Naranbhai V, Horowitz A, Qi Y, Martin MP, Yuki Y, Gao X, Walker-Sperling V, Del Prete GQ, Schneider DK, Lifson JD, Fellay J, Deeks SG, Martin JN, Goedert JJ, Wolinsky SM, Michael NL, Kirk GD, Buchbinder S, Haas D, Ndung'u T, Goulder P, Parham P, Walker BD, Carlson JM, Carrington M (2018) Elevated HLA-A expression impairs HIV control through inhibition of NKG2Aexpressing cells. Science 359:86-90

Reeves E, Colebatch-Bourn A, Elliott T, Edwards CJ, James E (2014a) Functionally distinct ERAP1 allotype combinations distinguish individuals with ankylosing spondylitis. Proc Natl Acad Sci U S A 111:17594-17599

Reeves E, Colebatch-Bourn A, Elliott T, Edwards CJ, James E (2015) Reply to Robinson and Brown: it is the combination of ERAP1 allotypes that identifies individuals with ankylosing spondylitis. Proc Natl Acad Sci U S A 112:E1817

Reeves E, Elliott T, James E, Edwards CJ (2014b) ERAP1 in the pathogenesis of ankylosing spondylitis. Immunol Res 60:257-269

Reith W, Mach B (2001) The bare lymphocyte syndrome and the regulation of MHC expression. Annu Rev Immunol 19:331-373

Robinson PC, Brown MA (2015) ERAP1 biology and assessment in ankylosing spondylitis. Proc Natl Acad Sci U S A 112:E1816

Sakaguchi S, Wing K, Miyara M (2007) Regulatory T cells - a brief history and perspective. Eur J Immunol 37(Suppl 1):S116-S123

Salter RD, Howell DN, Cresswell P (1985) Genes regulating HLA class I antigen expression in T-B lymphoblast hybrids. Immunogenetics 21 : 235-246

Shiina T, Inoko H, Kulski JK (2004) An update of the HLA genomic region, locus information and disease associations: 2004. Tissue Antigens 64:631-649

Spies T, Bresnahan M, Bahram S, Arnold D, Blanck G, Mellins E, Pious D, DeMars R (1990) A gene in the human major histocompatibility complex class II region controlling the class I antigen presentation pathway. Nature 348:744-747

Spies T, DeMars R (1991) Restored expression of major histocompatibility class I molecules by gene transfer of a putative peptide transporter. Nature 351:323-324

Spring B, Fonatsch C, Muller C, Pawelec G, Kompf J, Wernet P, Ziegler A (1985) Refinement of HLA gene mapping with induced B-cell line mutants. Immunogenetics 21:277-291

Staehli F, Ludigs K, Heinz LX, Seguin-Estevez Q, Ferrero I, Braun M, Schroder K, Rebsamen M, Tardivel A, Mattmann C, MacDonald HR, Romero P, Reith W, Guarda G, Tschopp J (2012) NLRC5 deficiency selectively impairs MHC class I-dependent lymphocyte killing by cytotoxic T cells. J Immunol 188:3820-3828

Steimle V, Otten LA, Zufferey M, Mach B (1993) Complementation cloning of an MHC class II transactivator mutated in hereditary MHC class II deficiency (or bare lymphocyte syndrome). Cell 75: $135-146$

Steinmetz M, Hood L (1983) Genes of the major histocompatibility complex in mouse and man. Science 222:727-733

Teng MS, Stephens R, Du Pasquier L, Freeman T, Lindquist JA, Trowsdale J (2002) A human TAPBP (TAPASIN)-related gene, TAPBP-R. Eur J Immunol 32:1059-1068

Timms RT, Menzies SA, Tchasovnikarova IA, Christensen LC, Williamson JC, Antrobus R, Dougan G, Ellgaard L, Lehner PJ (2016) Genetic dissection of mammalian ERAD through comparative haploid and CRISPR forward genetic screens. Nat Commun 7: 11786

Tonnelle C, DeMars R, Long EO (1985) DO beta: a new beta chain gene in HLA-D with a distinct regulation of expression. EMBO J 4:2839 2847

Townsend A, Ohlen C, Bastin J, Ljunggren HG, Foster L, Karre K (1989) Association of class I major histocompatibility heavy and light chains induced by viral peptides. Nature 340:443-448

Townsend AR, Gotch FM, Davey J (1985) Cytotoxic T cells recognize fragments of the influenza nucleoprotein. Cell 42:457-467

Tregaskes CA, Harrison M, Sowa AK, van Hateren A, Hunt LG, Vainio O, Kaufman J (2016) Surface expression, peptide repertoire, and thermostability of chicken class I molecules correlate with peptide transporter specificity. Proc Natl Acad Sci U S A 113:692-697

Trowsdale J, Hanson I, Mockridge I, Beck S, Townsend A, Kelly A (1990) Sequences encoded in the class II region of the MHC related to the 'ABC' superfamily of transporters. Nature 348:741-744

Trowsdale J, Kelly A (1985) The human HLA class II alpha chain gene $\mathrm{DZ}$ alpha is distinct from genes in the DP, DQ and DR subregions. EMBO J 4:2231-2237

Turner TR, Hayhurst JD, Hayward DR, Bultitude WP, Barker DJ, Robinson J, Madrigal JA, Mayor NP, Marsh SGE (2018) Single molecule real-time DNA sequencing of HLA genes at ultra-high resolution from 126 international HLA and immunogenetics workshop cell lines. HLA 91:88-101

van Ham SM, Tjin EP, Lillemeier BF, Gruneberg U, van Meijgaarden KE, Pastoors L, Verwoerd D, Tulp A, Canas B, Rahman D, Ottenhoff TH, Pappin DJ, Trowsdale J, Neefjes J (1997) HLA-DO is a negative modulator of HLA-DM-mediated MHC class II peptide loading. Curr Biol 7:950-957

Williams AP, Peh CA, Purcell AW, McCluskey J, Elliott T (2002) Optimization of the MHC class I peptide cargo is dependent on tapasin. Immunity 16:509-520

Zimmer J, Andres E, Donato L, Hanau D, Hentges F, de la Salle H (2005) Clinical and immunological aspects of HLA class I deficiency. QJM 98:719-727

Zinkernagel RM, Doherty PC (1974) Immunological surveillance against altered self components by sensitised T lymphocytes in lymphocytic choriomeningitis. Nature 251:547-548 